\title{
A scientist in American society
}

\section{Bernard Cohen}

The Rise of Robert Millikan: Portrait of a Life in American Science. By Robert $\mathrm{H}$. Kargon. Pp.204. ISBN 0-8014-1459-8. (Cornell University Press: 1982.) £18.15, $\$ 29.25$.

ROBERT Millikan, long considered the "dean" of American physicists, made contributions of significance to physics in three distinct areas: the determination of $e$ (the charge on the electron), the verification of Einstein's quantum equation for the photoelectric effect, and the study of cosmic rays. His achievements, however, proved to be less enduring than he must have hoped.

Millikan believed that his measurement of $e$ was an experimental fact, a monument for all time, but after a decade or more his value had to be rejected. His verification of Einstein's equation (yielding an exact value of Planck's constant) did not lead him to accept Einstein's quantum-theoretical explanation; as summed-up by Robert Kargon, "he sought to brake what he was to call Einstein's 'unthinkable,' 'bold,' and 'reckless' hypothesis of 'an electromagnetic light corpuscle of energy $h$ '." And although Millikan gave "cosmic rays" their name (they had been known as "penetrating radiation"), his theory that cosmic rays were photons produced by or associated with the formation of atoms on Earth came to be wholly rejected.

Professor Kargon, of the History of Science Department of Johns Hopkins University, has given us a sympathetic account of Millikan's scientific career, including his great triumphs, his rearguard actions to defend untenable positions, and the eventual rejection or revision of every major result or standpoint. But he is more concerned with Millikan's influence on the developing American physics community and with Millikan's role in advancing American science generally and American higher education. Together with the chemist A.P. Noyes and the astronomer G.E. Hale, Millikan developed a great centre for training young scientists. This group was able to attract large gifts for research from private individuals and philanthropic foundations (at a time when there were no government funds for this purpose), and its members were pioneers in group projects or interrelated projects that showed the future direction of most scientific research. They believed in an American scientific destiny and were convinced that American scientific greatness would be centred in the sunny climate of California. This picture of American science is presented with great insight, tremendous learning, and wit.

Because of the need to display the social or organizational features of American science (in which Millikan played so great a role), along with Millikan's scientific career, very often the information is too meagre to permit the reader fully to comprehend the issues. For example, much is made of the importance of Millikan's activities in organizing scientific research for military purposes during the First World War; this brought him into close contact with other leaders of American science, and with many other scientists, and established him as a national figure. But we are not really given any information concerning precisely what he did during the war years. Although the book is generally well written, there are editorial lapses, including the word-for-word repetition of the same quotation on pp.104 and 119. The index includes only names, so that one cannot readily locate the author's judicious and penetrating comments on such topics as the charge on the electron, cosmic rays and so on.

Professor Kargon's book strikes a happy balance between being an interpretive story of a scientific life and a social history of science in America. Every reader interested in science or in the place of science in society will come away from this book with new information, important insights and a better understanding of the growth of scientific ideas and institutions in the twentieth century.

I. Bernard Cohen is Victor S. Thomas Professor of the History of Science at Harvard University.

\section{Mysteries of the cell division cycle}

\section{Sydney Shall}

The Cell Division Cycle: Temporal Organization and Control of Cellular Growth and Reproduction. By David Lloyd, Robert K. Poole and Steven W. Edwards. Pp.523. ISBN 0-12-453760-X. (Academic: 1982.) £38.60, \$79.50.

WHY do cells reproduce at a particular frequency? Is it because they are growing as fast as the nutrient environment permits? This is possibly true for unicellular organisms, but clearly is not the case for complex multicellular organisms. Is cell reproduction totally dependent on growth factors (hormones), or are geometrical, topological and intrinsic genetic controls more important? Are the cell division cycles of prokaryotic and of eukaryotic organisms controlled by essentially different molecular mechanisms? Do faster-growing cells progress more quickly through the cell cycle, or is the fraction of cells that are non-dividers more significant? These questions are frequently asked and rarely answered. The subtitle of this book suggests that such problems can be tackled - an exciting prospect.

It is now over a decade since Mitchison published his invaluable monograph, The Biology of the Cell Cycle (Cambridge University Press, 1971), which is the benchmark for books on this subject. The present book is in some way a successor to that volume.

The temporal order of cellular reproduction is a central theme of The Cell Division Cycle. This sound and important concept is too often neglected by cell and molecular biologists, who seem to prefer structural analyses; these are (if I may borrow a phrase) necessary but insufficient conditions for understanding how cells behave. We have for too long ignored the temporal organization of cells and it is time to redress the balance. This book will help us on our way.

The authors discuss at some length the biosynthesis of macromolecules and of structures during the cell cycle, and there are also thorough accounts of energetics, transport and genetics. The available information for the lower eukaryotic organisms is clearly detailed. This volume gives a good contemporary account of these topics but the section on higher cells, particularly mammalian cells, is much less extensive. If the reader is interested in the control of cellular reproduction in mammalian cells, then I suggest that this book should be read in conjunction with David Prescott's concise but excellent Reproduction of Eukaryotic Cells (Academic, 1976). (It is, incidentally, to be hoped that Prescott will be prevailed upon to provide a second edition of his review.)

The present book achieves considerable success in concentrating our attention on the temporal order in cell reproduction. Although the subject is probably still in too primitive a state to be able to support a coherent description of the control of cellular growth and reproduction - except in Escherichia coli where we do have an overal and impressively sensible picture - the authors have managed to provide a reasonable picture of what we know about the cell division cycle in lower nucleated organisms. But for mammalian cells, we must await another book.

Sydney Shall is the Professor in the Cell ana Molecular Biology Laboratory at the University of Sussex. 